\title{
Producción de textos argumentativos publicitarios sobre promoción lectora. Propuesta en la formación inicial de docentes
}

\section{Production of Argumentative Advertising Texts on Reading Promotion: Proposal for Initial Teacher Training}

\author{
Produção de textos publicitários argumentativos sobre \\ promoção da leitura. Proposta na formação inicial de \\ professores
}

\section{David Mauricio Giraldo Gaviria}

Magíster en Ciencias de la Educación; Estudiante del Doctorado en Ciencias de la Educación; Licenciado en Pedagogía Infantil; Normalista Superior y Docente de Práctica Pedagógica Investigativa del Programa de Formación Complementaria de la Escuela Normal Superior del Quindío.

\section{OPEN ACCESS $\boldsymbol{\Omega}$ \\ DOI: http://dx.doi.org/10.18634/sophiaj. 17v.1i.1103}

Información del artículo

Recibido: octubre 09 de 2020

Revisado: noviembre 14 de 2020

Aceptado: febrero 12 de 2021

Publicado: abril 15 de 2021

Palabras clave: didáctica de la Lengua Materna, figuras retóricas, Modelo Didactext , promoción lectora, texto argumentativo.

Keywords: modern tongue didactics, argumentative text, rhetorical figures, Reading promotion, Didactext model.

palavras-chave: didática da língua moderna, texto argumentativo, figuras retóricas, promoção da leitura, modelo Didactext.

Cómo citar: /how cite:

Giraldo, D.M (2021) Producción de textos argumentativos publicitarios sobre producción lectora. Propuesta en la formación inicial de docentes. Sophia, 17(1), e1103.

Sophia-Educación, volumen 17 número 1. enero/junio 2021. Versión español

\section{RESUMEN}

La presente investigación tuvo como objetivo general potenciar la producción argumentativa publicitaria de los estudiantes del Programa de Formación Complementaria de la Escuela Normal Superior del Quindío. Lo anterior debido a que carecen de habilidades argumentativas e identificación de géneros propios de la argumentación, elaboración de puntos de vista, deliberaciones, manejo de argumentos y debates. Tal propósito llevó a tres acciones específicas planteadas así: el diagnóstico del nivel de competencia argumentativa de los estudiantes; la identificación de los factores contextuales que influyen en el desarrollo de la producción argumentativa y la indagación de algunas teorías para el diseño e implementación de un proyecto que potencie la producción argumentativa sobre la promoción lectora. La metodología utilizada correspondió a la Investigación Acción, a partir de los planteamientos de Jhon Elliott y Miguel Martínez, con sus 9 fases de investigación en el aula y desde un enfoque Crítico social. Los resultados obtenidos vislumbran la necesidad de implementar las habilidades argumentativas desde sus diversos géneros discursivos; a su vez, se muestra el dinamismo del Modelo Didactext (2015) el cual evidencia ser adaptable a diversas tipologías textuales; en este caso específico, a la argumentativa y al género discursivo de la publicidad. No podría aseverarse que con la intervención se solucionó por completo la problemática existente en torno a la argumentación, puesto que el fomento de actitudes argumentativas es inacabable y, por ello, se busca incentivar el interés de los estudiantes frente a las situaciones de carácter lector que los apremian. 
Copyright 2021 Universidad La Gran Colombia

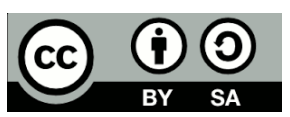

Conflicto de interés:

Los autores declaran no tener ningún conflicto de interés.

Correspondencia de autor:

davgiraldo@ensq.edu.co

\section{ABSTRACT}

The general objective of this research was to enhance the argumentative advertising production of the students of the Complementary Training Program of the Escuela Normal Superior del Quindío. This is due to the fact that they lack argumentative skills and identification of argumentation genres, elaboration of points of view, deliberations, management of arguments and debates. This purpose led to three specific actions: the diagnosis of the level of argumentative competence of the students; the identification of the contextual factors that influence the development of argumentative production and the investigation of some theories for the design and implementation of a project that enhances the argumentative production on reading promotion. The methodology used corresponded to Action Research, based on the approaches of Jhon Elliott and Miguel Martinez, with its 9 phases of research in the classroom and from a Social Critical approach. The results obtained show the need to implement argumentative skills from different discursive genres; at the same time, the dynamism of the Didactext Model (2015) is shown, which is adaptable to different textual typologies; in this specific case, to the argumentative typology and to the discursive genre of advertising. It could not be asserted that the intervention completely solved the existing problems related to argumentation, since the promotion of argumentative attitudes is endless and, therefore, it seeks to encourage the interest of students in reading situations that urge them to read.

\section{RESUMO}

A presente pesquisa teve o objetivo geral de promover a produção publicitária argumentativa dos alunos do Programa de Formação Complementar da Escola Normal Superior do Quindío. Isso se deve ao fato de carecerem de habilidade argumentativa e identificação dos gêneros de argumentação, elaboração de pontos de vista, deliberações, manejo de argumentos e debates. Este propósito conduziu a três ações específicas que se seguem: o diagnóstico do nível de competência argumentativa dos alunos; a identificação dos fatores contextuais que influenciam o desenvolvimento da produção argumentativa e a investigação de algumas teorias para a concepção e implementação de um projeto que valorize a produção argumentativa na promoção da leitura. A metodologia utilizada correspondeu à Investigação-Ação, baseada nas abordagens de Jhon Elliott e Miguel Martínez, com as suas 9 fases de investigação em sala de aula e a partir de uma abordagem sócio-crítica. Os resultados obtidos revelam a necessidade de implementação de habilidades argumentativas a partir de seus diversos gêneros discursivos; por sua vez, mostra-se o dinamismo do Modelo Didactext (2015), o que mostra que é adaptável a várias tipologias textuais; neste caso específico, à tipologia argumentativa e ao gênero discursivo da publicidade. Não se poderia afirmar que a intervenção resolveu completamente o problema existente em torno da argumentação, uma vez que a promoção de atitudes argumentativas é interminável e, portanto, busca despertar o interesse dos alunos pelas situações de leitura que os instigam. 


\section{Introducción}

La presente investigación denominada Producción de textos argumentativos publicitarios sobre promoción lectora. Una propuesta dirigida a estudiantes del Programa de Formación Complementaria (PFC) de la Escuela Normal Superior del Quindío (ENSQ) se ejecuta en el marco de la Maestría en Ciencias de la Educación de la Universidad del Quindío; la situación problemática llevó a determinar que los docentes en formación no producen con éxito textos de carácter argumentativo y que la enseñanza de la lengua y, en concreto, de la argumentación no tiene un enfoque funcional que permita a los estudiantes exponer sus ideas eficazmente. Dicha situación conduce a que no se generen espacios, para que estos aprendan a construir textos argumentativos a través de diversos géneros discursivos. De otro lado, los estudiantes revelan desconocimiento de la competencia argumentativa en los diferentes escenarios, en tanto que el desarrollo de las prácticas de escritura se limita a un enfoque gramatical que se aleja de un enfoque funcional comunicativo (Álvarez, 2005).

Ante la complejidad de este reto, surge la posibilidad de aprovechar la predilección natural de estos jóvenes maestros por los medios masivos de comunicación para fortalecer su potencial argumentativo con el lenguaje de la imagen y la comunicación de masas, elementos que permean sus concepciones del mundo; de ahí la elección de un género discursivo como el afiche publicitario enfocado a un tema de vital preocupación para su quehacer futuro: la comprensión de lectura. Esta sería una primera tarea que, desde las observaciones recogidas, podría rendir frutos importantes, con miras al fortalecimiento posterior de producción argumentativa en otros géneros como el debate, la ponencia, el ensayo, etc.

En este orden de ideas, se plantea como objetivo general potenciar la producción argumentativa publicitaria de los estudiantes del programa de formación complementaria de la Escuela Normal Superior del Quindío, del cual se desprenden los siguientes objetivos específicos: 1) diagnosticar el nivel de competencia argumentativa de los estudiantes; 2) identificar los factores contextuales que influyen en el desarrollo de la producción argumentativa; y 3) examinar algunas teorías para el diseño e implementación de un proyecto que potencie la producción argumentativa sobre la promoción lectora.

Lo anterior, permitió formular la pregunta de investigación: ¿Cómo potenciar la producción argumentativa publicitaria sobre promoción lectora de los estudiantes del programa de formación complementaria de la Escuela Normal Superior del Quindío?, la cual conduce a la identificación y categorización de algunas de las problemáticas en relación con la competencia argumentativa de los estudiantes. En el intento de imaginar la respuesta a dicha pregunta, en tal contexto se enunció la siguiente hipótesis: Los estudiantes partícipes de la investigación podrían potenciar el desarrollo de habilidades relacionadas con la argumentación publicitaria, mediante la implementación de una secuencia que permita intervenir las dificultades identificadas y, de esta manera, brindar herramientas para que ellos comprendan la relevancia de la persuasión publicitaria en el contexto, e identificar el papel que juega el tejido entre imagen y texto mediado por estrategias retóricas que mejoren producción de escritura por medio de la publicidad sobre promoción lectora.

La validación de dicha hipótesis corrió por cuenta de las teorías relacionadas con la didáctica de la lengua materna (Camps, 1993, 2011, 2005) y la transposición didáctica (Chevallard, 1985, 1998; Álvarez, 1998; Dolz, 1995; Dolz, Gagnon, y Mosquera, 2009). Por el lado de la argumentación, se asumió la concepción argumentativa publicitaria (Lomas, 1996, 1999). Además, se le dio una mirada a los géneros discursivos (Bajtín, 1982) y al modelo sociocognitivo, pragmalingüístico y didáctico (Didactext, 2015).

Para la realización de esta investigación, llevada a cabo durante dos años, se utilizó el diseño de la Investigación Acción Participación (IAP) desde la perspectiva de Martínez (2010), quien siguiendo a Elliott (2005) propone nueve fases, a saber: 1) diseño general del proyecto; 2) identificación de un problema importante; 3) análisis del problema; 4) formulación de la hipótesis; 5) recolección de la información necesaria; 6) categorización de la información; 7) estructuración de las categorías; 8) diseño y ejecución de un plan de acción y 9) evaluación de la acción ejecutada. La propuesta de intervención se ejecutó con dieciocho estudiantes de V semestre del Programa de Formación Complementaria, en el marco del espacio académico denominado Práctica pedagógica investigativa, con una intensidad de 4 horas semanales durante todo el semestre.

Es importante destacar que, si bien se busca potenciar la producción de textos argumentativos desde el ámbito cercano de la promoción lectora, los resultados pueden representarse desde cuatro frentes: 1) concepto de leer y su aplicabilidad en la promoción lectora; 2) banco de publicidad sobre promoción lectora; una mirada a la imagen y el eslogan; 3) figuras retóricas en la publicidad desde la percepción semántica, morfosintáctica, fonética y pragmática y 4) adaptación del modelo Didactext (2015); una mirada a la publicidad en la escuela 
(Péninou, 1972).

Se reconoce, en última instancia, que ante el vasto panorama investigativo que se advierte, el proyecto se constituye en una primera aproximación al reto de potenciar la producción argumentativa en el PFC, como elemento relevante en la enseñanza del lenguaje (Ministerio de Educación Nacional, 1998, 2013). Por último, se entiende que el fomento de actitudes argumentativas es inagotable y, en consecuencia, se busca incentivar el interés de los estudiantes frente a las situaciones de carácter lector que los apremian a través de un género cercano como la publicidad, con la intención de despertar en esta nueva generación de docentes intereses escriturales.

\section{Transposición didáctica: del saber sabio al saber enseñado, desde la perspectiva de Yves Chevallard; una aproximación al concepto}

Diversos autores e investigadores en didáctica están de acuerdo en reconocer que el concepto de transposición didáctica se debe a Michel Verret, quien la define como "la transmisión de aquellos que saben a aquellos que no saben. De aquellos que han aprendido a aquellos que aprenden" (1975: 39). Posteriormente, en el año de 1985, el concepto fue retomado por el francés Yves Chevallard, quien en un principio se interesa por la interacción entre docente, alumnos y conocimiento. Estos tres elementos constituyen un llamado sistema didáctico y la relación tripartita entre ellos se concibe como la relación didáctica. Paralelamente, Chevallard plantea la importancia de la relación entre el saber y el saber enseñado, en estos términos:

"un contenido del saber sabio que haya sido designado como saber a enseñar sufre a partir de entonces un conjunto de transformaciones adaptativas que van a hacerlo apto para tomar lugar entre los objetos de enseñanza. El 'trabajo' que un objeto de saber a enseñar hace para transformarlo en un objeto de enseñanza se llama transposición didáctica" (Chevallard, 1998:39).

Por otra parte, Chevallard considera que un sistema didáctico está constituido por un sistema de enseñanza y que a su vez se encuentra implícito en un ámbito más amplio: la sociedad. Todo sistema didáctico que es permeado por un sistema de enseñanza constantemente se enfrenta al debate social; igual ocurre con la situación de interrelación entre sujetos que se enfrentan a situaciones problémicas nacientes de la sociedad y sus nuevas exigencias, tal como lo asume Chevallard (1985). Es decir, el lugar donde se construye y se lleva a la práctica el funcionamiento didáctico como noosfera, se entiende como la esfera constituida por los agentes emergentes del contexto inmediato, que a su vez se constituyen en representantes del sistema de enseñanza, representantes de la sociedad y expertos en la materia específica.

\section{Aproximación conceptual en relación con los géneros discursivos}

Se presenta, sucintamente, una aproximación a la noción de género discursivo, con la intención de seguir marcando el horizonte de esta propuesta investigativa; en este sentido, tomamos como referente lo planteado por Bajtín , así: "La riqueza y diversidad de los géneros discursivos es inmensa, porque las posibilidades de la actividad humana son inagotables y porque en cada esfera de la praxis existe todo un repertorio de géneros discursivos que se diferencia y crece a medida que se desarrolla y se complica la esfera misma".

Parafraseando a Bajtín (1982), el uso de la lengua se pone en marcha de acuerdo con la forma de los enunciados; estos manifiestan las condiciones concretas y el objeto de cada una de las esferas, no solo por su contenido temático y por su estilo verbal, o sea por la selección de los recursos léxicos y gramaticales de la lengua, sino, ante todo, por su estructuración. Esta definición de género discursivo permite visualizar tres elementos importantes: el contenido, el estilo verbal y la estructuración, que dan cuenta de las diferencias entre uno y otro género, lo que consigue establecer formas típicas relativamente estables; es decir, para Bajtín (1982), cada esfera del uso de la lengua elabora sus tipos relativamente estables de enunciados, a los que denominamos géneros discursivos.

Se puede decir, a manera de conclusión, que los géneros discursivos son propios del acontecer histórico de la humanidad; se dan como resultado de las relaciones entre las personas y las comunidades, mediadas por normas, convenciones y, desde luego, por su finalidad. Actualmente se develan nuevos géneros discursivos concebidos por el avance de la tecnología, tales como el chat, el email, las teleconferencias, las redes sociales, entre otros. Igualmente, podemos dar cuenta de otros que desaparecieron como el telegrama, las radio novelas, la tradición oral de contar historias. En este marco, posteriormente se abordará el afiche publicitario 
(con tema específico de promoción lectora), como género discursivo de la argumentación que ofrece ventajas importantes para el trabajo con nuevas generaciones de maestros que han nacido en medio del apogeo de la imagen, la brevedad y la difusión masiva de bienes y servicios, en el marco de una revolución tecnológica y de globalización en la comunicación.

\section{La publicidad: postura argumentativa desde la perspectiva de Carlos Lomas}

La imagen retiene momentos y determina sucesos, sintetiza un recuerdo que establece un itinerario de situaciones significativas para quien las observa; los colores, las texturas, las formas al unísono se conjugan para la representación de un recuerdo, un sueño o simplemente un deseo. Por ello, la correlación armónica de todos los elementos da paso a la llamada publicidad que se interpreta "como uso comunicativo que aúna lo icónico, lo gráfico, lo sonoro, lo verbal y lo no verbal, la publicidad aparece en nuestras sociedades como un mosaico de prácticas discursivas en las que los objetos entran, a través de complejas redes de connotación, en el territorio del signo" (Lomas, 1996: 25).

Las prácticas discursivas que rondan las aulas de clases y que atañen a los deseos, a la ensoñación y al gusto están permeadas por la acción de los medios audiovisuales, los cuales se presentan como instrumentos más fascinantes, llamativos, de fácil acceso y que dirigen el actuar pedagógico del maestro y que, de igual manera, reflejan lo enseñado en las escuelas (Dietcher, 1963). Las puertas del texto publicitario permiten visualizar lo que desde un inicio retiene la mirada con su capacidad retórica y reflejan la vida social del alumnado, por consiguiente, "la publicidad instruye a la infancia, a la adolescencia y a la juventud que acude de lunes a viernes a nuestros centros de enseñanza” (Lomas, 1992).

Dicho esto, es visible que los usos comunicativos que se han dado a la publicidad permiten ver el poder que tiene la imagen sobre la construcción de cultura; ella le da vigencia a formas concretas de percibir el mundo y a formas de comunicación que orientan los ideales grupales y personales en la construcción social, ideológica y política. En este escenario, la publicidad demuestra que "nuevas formas de comunicación orientan nuestras percepciones y guían nuestros actos a través de diversos usos verbales y no verbales de persuasión que persiguen un consenso ideológico en nuestras sociedades similar al consenso lingüístico que hace posible que una comunidad de habla establezca intercambios orales y escritos en su seno" (Lomas, 1996: 16).

El mensaje simbólico se mueve en diversos sistemas verbales y no verbales e impacta desde la persuasión publicitaria, como medio contemporáneo que inunda las percepciones y el entorno sociocultural; por lo tanto, el papel que ejecutan los mensajes de las industrias determinan los ideales de las personas y el significado que le dan a los mismos. Ahora, el impacto social de la publicidad provoca acciones y sentimientos en el público que lo recibe; es así como "los usos y las formas de la comunicación publicitaria, en su reiteración inevitable de tópicos y connotaciones y en su afán de estimular los deseos y aspiraciones individuales y sociales de las personas, contribuyen de forma utilísima al actual proceso de tematización en nuestras sociedades" (Lomas, 1996: 18).

Por otra parte, el poder que la publicidad ejerce continuamente en las esferas sociales ofrece un espectáculo de convencimiento para los receptores a quienes se les hace creer lo imposible, lo intangible o sencillamente lo real; "el lenguaje de la publicidad no es sino un tipo específico de discurso que obedece a determinadas condiciones de enunciación y recepción, tiene una intencionalidad concreta, se inscribe en contextos culturales precisos y se halla marcado de forma expresa, de tal forma que es habitualmente reconocido por sus destinatarios sin ninguna dificultad" (Lomas, 1996: 28).

Desde esta perspectiva, se puede instalar la necesidad de responder y determinar a la publicidad como el medio que contextualiza los diferentes tópicos de la cultura que se incorporan en contextos comunicativos concretos. Lo concebimos como entramado de aquellas circunstancias que asumen el fin de vender una imagen que se cataloga como adecuada o propia de los escenarios reales, con la intención de invadir el inconsciente para construir modos de vida de acuerdo con los paradigmas culturales.

Esta síntesis teórica que se ha esbozado constituye el fundamento epistemológico que da cimiento al estudio; estos son el punto de partida para elaborar la propuesta de intervención que pretende responder a la situación problemática abordada.

\section{Materiales y métodos}

Debido a la naturaleza del presente estudio, utilizamos el método de Investigación Acción Participación (IAP), desde la mirada de Elliott (2005), quien define este paradigma así: 
La investigación-acción se concibe como el estudio de una situación social para tratar de mejorar la calidad de la acción en la misma. Su objetivo consiste en proporcionar elementos que sirvan para facilitar el juicio práctico en situaciones concretas, y la validez de las teorías e hipótesis que genera no depende tanto de pruebas "científicas" de verdad, sino de su utilidad para ayudar a las personas a actuar de modo más inteligente y acertado (88)

La investigación-acción implica necesariamente la autorreflexión de los participantes sobre la situación que se presenta como problémica; describe y explica las situaciones sociales de la vida diaria; los hechos se interpretan como acciones y transacciones humanas, en vez de procesos naturales sujetos a las leyes de la ciencia. Somos conscientes, además, de que los procesos investigativos permeados por la IAP requieren de un mayor tiempo para su actuación; sin embargo, aunque en nuestro caso la duración fue de seis meses, podríamos decir que aún así esta experiencia se inscribe en esta modalidad IAP, ya que en este tiempo se gestaron cambios actitudinales significativos y se propiciaron transformaciones en la manera de afrontar estos complejos procesos de comprensión y producción textuales por parte de estos estudiantes, futuros docentes.

La elaboración de esta propuesta investigativa se ejecuta desde el enfoque de la IAP, la cual se llevó a cabo a partir de las etapas propuestas por Martínez (2010) quien las expone de acuerdo con la propuesta de Elliott, a saber : 1. Diseño general del proyecto; 2. Identificación de un problema importante; 3. Análisis del problema; 4. Formulación de la hipótesis; 5. Recolección de la información necesaria; 6. Categorización de la información; 7. Estructuración de las categorías; 8. Diseño y ejecución de un plan de acción; 9. Evaluación de la acción ejecutada

La investigación se ejecutó en la Institución Educativa Escuela Normal Superior del Quindío, de carácter público, conformada por cuatro sedes educativas, Rojas Pinilla, Fundanza, República de Uruguay y Central. Actualmente, oferta los niveles de educación preescolar, básica, media y Programa de Formación Complementaria; atiende una población de 2700 estudiantes aproximadamente pertenecientes generalmente a los estratos socioeconómicos 2, 3 y 4.

\section{Resultados}

A continuación, se da cuenta de las acciones realizadas alrededor del proceso de intervención y sus aportes para la consecución de los objetivos. La información se distribuye en 4 momentos: 1) Concepto de leer y su aplicabilidad en la promoción lectora; 2) Banco de publicidad sobre promoción lectora. Una mirada a la imagen y al eslogan; 3) Figuras retóricas en la publicidad desde la percepción semántica, morfosintáctica, fonética y pragmática y 4) Adaptación del Modelo Didactext (2015). Una mirada a la publicidad en la escuela.

A partir de los anteriores momentos se presentan los resultados, tomando como base la codificación, la categorización y la triangulación de la información, lo cual fue posible desde las instancias del diario de campo, el análisis de contenido y las listas de verificación. Dichos resultados permitieron visualizar los hallazgos, en relación con la producción de textos argumentativos publicitarios sobre promoción lectora y con la efectividad en la implementación de la secuencia didáctica.

Para el desarrollo de la secuencia didáctica se generaron guías de aprendizaje, cada una estaba elaborada con una misma estructura ordenada en 4 fases o ciclos tomando como referencia las estrategias cognitivas y metacognitivas del Modelo Didactext (2015); los momentos de la guía fueron Lee el mundo, Lee para saber, Lee para escribir y Lee para mejorar.

Cada fase, por supuesto, buscó el desarrollo del trabajo autónomo y participativo; desde los principios metodológicos de la IAP, partieron del diálogo entre estudiantes y priorizaron el trabajo grupal, al igual que permitieron la construcción de aprendizajes desde la reflexión paso a paso. A continuación, encontramos el análisis elaborado de acuerdo con las categorías enunciadas en el capítulo anterior; allí también se citan algunos de los comentarios hechos por los estudiantes a lo largo de la secuencia didáctica.

\section{Concepto de leer y su aplicabilidad en la promoción lectora}

IInicialmente, para el desarrollo de la guía de aprendizaje, se puso en discusión el concepto de leer; se generó un diálogo acerca de la incidencia que tiene la acción de leer en la vida académica, personal y social. Como complemento de lo anterior se recabaron los planteamientos del Plan Nacional de Lectura Leer es mi cuento, del Ministerio de Educación Nacional (2006); allí se consideran "la lectura y la escritura como prácticas íntimas, estéticas, de acceso y producción de conocimiento, pero también como prácticas sociales y culturales desde donde podemos alcanzar el ejercicio de la ciudadanía plena" (6). 
Acto seguido, se exploran diversas clases de textos, los cuales mostraban la funcionalidad que puede tener la acción lectora; además, se indagó sobre las diferentes tipologías y los contextos en que es utilizada la lectura. Se analizó el hecho de que leemos en las clases de matemáticas, de ética, de ciencias sociales; también indagamos sobre las circunstancias en que leemos el mundo desde distintas expresiones del lenguaje hasta llegar a la conclusión que plantea el Plan Nacional de Lectura (2013): “la lectura no solo se circunscribe exclusivamente solo al ámbito escolar y tampoco se restringe solamente a las áreas de Lenguaje y Literatura" (8).

Para la construcción del concepto de leer, la actividad se dividió en tres momentos: primero, se elabora el concepto individual, el cual partió de los saberes previos de los estudiantes, de las experiencias que consideraron pertinentes nombrar y básicamente del conocimiento del mundo que poseían. Segundo, cada estudiante compartió su concepto de leer, luego los discutimos a nivel grupal, y posteriormente, se reunieron en grupos de cuatro miembros y elaboraron un concepto grupal.

Hasta este punto tan solo se utilizaron argumentos de ejemplificación y analogía, puesto que se elaboraron los conceptos de acuerdo con lo considerado por cada grupo. Prosiguiendo con la actividad, en tercer lugar, elaboramos un concepto a la luz de algunos planteamientos teóricos emanados por el Ministerio de Educación Nacional, y específicamente, en Prácticas de lectura en el aula. Orientaciones pedagógicas para docentes, documento publicado en el año 2014.

Es importante aclarar que, el horizonte que regía la intervención se fundamentaba en la producción argumentativa por parte de los estudiantes del PFC; en este orden de ideas se apuesta por el género discursivo del afiche (poster) publicitario, en razón de que este género discursivo es un puente que fundamenta la estructura argumentativa y que posibilita trabajar, posteriormente, con géneros discursivos más complejos. Por consiguiente, fue necesario realizar otras categorías de análisis, en las cuales trabajar de manera más amplia: algunas generalidades de la producción de textos argumentativos publicitarios sobre motivación lectora.

\section{Banco de publicidad sobre promoción lectora. Una mirada a la imagen y al eslogan}

El desarrollo del concepto de afiche publicitario lo centramos en un primer momento en mirar dos elementos generales que este conjuga. Por un lado, la imagen, definida por la Real Academia de la Lengua como "figura, representación, semejanza y apariencia de algo"; y por el otro, el eslogan, considerado por Lomas (1996: 92) como: "el lema filosófico y religioso o la consigna política, convincente, breve y fácil de recordar y de contener un solo argumento (una idea clara y concreta) y a la vez aludir a aquello que el consumidor obtendrá (de forma real o figurada) como consecuencia de la adquisición del objeto".

De acuerdo con los objetivos de las guías aprendizaje los estudiantes indagaron en las redes en busca de imágenes y afiches publicitarios que tuvieran relación con la promoción lectora. De acuerdo con el rastreo hecho, pudimos elaborar un banco de publicidad con 100 imágenes alusivas que se constituyó en la base de trabajo para el desarrollo de las sesiones siguientes.

Para fortalecer el análisis se realiza lectura del libro de Carlos Lomas El espectáculo del deseo. Usos y formas de la persuasión publicitaria, y específicamente, el capítulo 4 sobre "lo obvio y lo obtuso", con la intención de reconocer algunas generalidades de los textos argumentativos publicitarios recogidos. Esta actividad permitió elaborar en conjunto una lista de verificación (rúbrica) para la revisión y análisis del banco de publicidad. De mutuo acuerdo, los aspectos resaltados para revisar fueron los siguientes: 1) Propósito del afiche publicitario; 2) Intención Persuasiva; 3) Recursos Icónicos; 4) Consistencia; 5) Originalidad y Contextualización y 6) Ortografía y redacción.

Los afiches publicitarios compilados fueron de gran utilidad, pues estos facilitaron una mirada amplia de las formas de persuasión publicitaria y, de igual modo, indujeron a reflexionar sobre la publicidad desde aspectos como color, forma, intención, contexto... Por otra parte, los estudiantes hicieron este ejercicio con los 100 afiches publicitarios de promoción lectora encontrados en la red. Según los datos analizados, a partir de la lista de verificación (rúbrica), se obtuvo un panorama más amplio acerca de las perspectivas en las que se mueve la publicidad sobre promoción lectora y de qué manera busca persuadir un público (Perelman, 1989).

Gran parte de los afiches publicitarios analizados poseen argumentos que traspasan la barrera de lo tangible y del texto literal. Esto dialoga con la posición de Lomas (1996: 18): “Ios usos y formas de la comunicación publicitaria, en su reiteración inevitable de tópicos y connotaciones y en su afán de estimular los deseos y aspiraciones individuales y sociales de las personas, contribuyen de forma utilísima al actual proceso de 
tematización en nuestras sociedades". Desde esta perspectiva, si no se logra un efecto persuasivo, no se alcanza a marcar la memoria colectiva del público al que deseamos adherir.

En el análisis del banco de publicidad se encuentra que los afiches tienen como punto de partida el trabajo social; es decir, permiten ver la lectura como una acción liberadora, como acción de crecimiento en los ámbitos académicos y personales, hacen un énfasis amplio en el desarrollo de la imaginación; gran parte de los afiches mostraban un nivel óptimo, lo cual dice que presentan una idea propia y novedosa, pudiendo integrar elementos existentes pero reelaborándolos e interpretándolos, o apelando a aspectos del contexto social y cultural de los receptores a los que se está dirigiendo el afiche.

Es por esto que, los resultados de la actividad ofrecieron un panorama amplio sobre la publicidad orientada a la motivación lectora en diferentes espacios, bien en el caso de Ministerios de Educación o bien desde instituciones privadas en diversos países de Iberoamérica. No se puede olvidar que la publicidad permea los paisajes urbanos de todos los medios; en este caso, recapitulando a Lomas (1996: 92) podemos decir que: "en efecto, en su afán de seducir y convencer al lector o al espectador de los mensajes publicitarios, quienes enuncian anuncios no solo utilizan imágenes orientadas a desplegar el universo simbólico de las connotaciones. Usan, además, el poder de la palabra".

Hacia el final del ejercicio de análisis del banco de publicidad, se buscó que los estudiantes elaboraran un primer afiche publicitario. Este afiche fue realizado a partir de sus saberes previos. Se consideró que después de revisado el concepto de leer y el análisis del banco de publicidad, los estudiantes tenían los insumos necesarios para producir un afiche en versión de borrador. Cabe aclarar que, los docentes en formación conocían de teoría de color y distribución de planos y formas, puesto que en la Escuela Normal Superior del Quindío han recibido formación en artes, desde el nivel de Básica Secundaria hasta que finalizan el Programa de Formación Complementaria.

\section{Figuras retóricas en la publicidad desde la percepción semántica, morfosintáctica, fonética y pragmática}

Continuando con el propósito designado en las guías de aprendizaje el ejercicio se centró en mirar en detalle algunas figuras retóricas utilizadas en el lenguaje publicitario; de acuerdo con las apreciaciones de Lomas (1999: 280) "la retórica estudia los usos lingüísticos y las estrategias comunicativas utilizadas por las personas para persuadir y convencer a otras personas. De ahí que sea sutil no solo para conocer los diferentes usos y efectos de las palabras sino también de la imagen, especialmente de una imagen tan persuasiva como la publicitaria". Para nuestro fin, nos centramos en mirar las figuras retóricas en cuatro apartados, desde los usos: 1) fónicos; 2) Morfosintácticos; 3) semánticos y 4) pragmáticos. En la siguiente tabla 1 se abordan las figuras retóricas utilizadas desde dicha clasificación:

Tabla 1. Usos de las figuras retóricas

\begin{tabular}{cccc}
\hline Usos fónicos & Usos semánticos & $\begin{array}{c}\text { usos } \\
\text { morfosintácticos }\end{array}$ & Usos pragmáticos \\
\hline Aliteración & Sinécdoque & Anáfora & Exhortación \\
Onomatopeya & Hipérbole & Concatenación & Afirmación \\
Rima & Metáfora & & Personificación \\
\hline
\end{tabular}

Fuente: elaborado por el autor

Valga recordar la amplia variedad de figuras retóricas elaboradas por los estudiantes, algunas de las cuales reposan en las guías de aprendizaje realizadas por ellos mismos. A continuación, ciertos productos elaborados se muestran en la tabla 2. 
Tabla 2. Figuras retóricas realizadas durante las sesiones

$\begin{array}{ll}\text { Figuras retóricas de orden fónico: } & \begin{array}{l}\text { Figuras retóricas de orden } \\ \text { morfosintáctico: }\end{array}\end{array}$

Rima: 1,2,3, vamos a leer

Anáfora: ¡Anímate a crecer, anímate a aprender, anímate a leer!

Onomatopeya: ¡PUM! Leer genera ideas

Figuras retóricas de orden semántico:

Hipérbole: ¡Un millón de veces te han dicho que leer es importante!

Metáfora: Leer para soñar despierto.

Figuras retóricas de orden
pragmático:

Afirmación: ¡Todos a leer! Léelo.
Exhortación: ¡Ya tienes el libro!

\section{Fuente: Elaborada por el autor}

Finalizada la segunda versión de los afiches publicitarios, el ejercicio buscó a revisar cada uno de los afiches producidos, con el apoyo de la ficha de verificación (rúbrica); pero con los resultados del análisis se vio la necesidad de realizar una tercera y última versión de los afiches publicitarios.

\section{Adaptación del Modelo Didactext: una mirada a la publicidad en la escuela}

El desarrollo de las sesiones de intervención se enfocó en el trabajo plasmado por guías de aprendizaje. En este punto, es necesario hacer hincapié en que cada guía de aprendizaje buscó realizar una adaptación de las estrategias cognitivas y metacognitivas del Modelo sociocognitivo, pragmalingüístico y didáctico para la producción de textos escritos; Modelo Didactext (2015); en este punto podemos decir que, la elaboración de la versión final del afiche publicitario fue posible gracias a los aportes de cada una de las estrategias del modelo adoptado. El siguiente recuento muestra de manera generalizada el proceso de producción del afiche final:

Acceso al conocimiento (Lee el mundo): La ejecución de la intervención se orientó hacia la búsqueda de un tópico específico; además, partiendo del concepto de texto, se reconocen saberes previos de los estudiantes; del mismo modo, se encontró en la producción de los afiches publicitarios un punto de encuentro entre el desarrollo de procesos argumentativos e interés en promocionar la lectura. valga aclarar que, se aprovechó el género discursivo de la publicidad, puesto que se presenta como un medio agradable, llamativo y de interés para los estudiantes; no obstante, en este punto preestablecimos los posibles resultados que se esperaban del producto por realizar (afiche publicitario sobre promoción lectora).

Planificación. (Lee para saber): Las guías de aprendizaje, como elementos de planificación del trabajo, partían de un objetivo específico, pues la intención siempre fue optimizar el afiche publicitario; así mismo, la planificación del trabajo que se exponía en las guías permitió la producción de afiches acordes con lo presupuestado. De igual manera, estas no solo exponían las instrucciones de trabajo, sino que permitieron clasificar la información de acuerdo con las necesidades de cada sesión. Estas mostraban paso a paso lo que los estudiantes debían realizar y, a su vez, permitían llevar un orden de las metas trazadas para cada encuentro.

Producción textual (Leer para escribir): El trabajo pensado y ejecutado se realizó en torno al reconocimiento del género discursivo de la publicidad; así, cada uno de los momentos que se presentan en la intervención era pensado con una intencionalidad definida: la producción de textos argumentativos publicitarios sobre 
promoción lectora. Para ello se elaboraron distintos borradores intermedios, que en este caso se llaman afiches publicitarios versiones 1, 2 y 3; al igual que, se buscaba que en el desarrollo de las sesiones los estudiantes pensaran a qué público iba dirigida la información.

Revisión (Lee para criticar y revisar): Para la revisión de los borradores intermedios, una de las herramientas pensadas desde la planificación fue la lista de verificación (rúbrica), la cual permitió durante el proceso realizar el análisis continuo de lo planteado para cada sesión; esto condujo a establecer momentos de comparación, inferencia y reflexión frente a lo realizado, por lo que se pudieron resolver problemas relacionados con el tema, la intención y los sujetos a quienes se buscaba persuadir.

\section{Conclusiones}

Los estudiantes lograron elaborar un nuevo concepto de leer; partieron de reconocer que sus proposiciones eran fundamentalmente doxásticas y al profundizar en la teoría construyeron un concepto más epistémico, que va más allá de la decodificación y reconoce el valor interactivo, pragmático y cultural. El trabajo de intervención incidió en la elaboración de esta nueva concepción y resulta interesante verificar que los estudiantes acoplaron las discusiones teóricas a la revisión del corpus conseguido sobre afiches publicitarios en promoción de lectura. La siguiente proposición es una de las tantas realizadas por los estudiantes que respaldan lo anteriormente expuesto.

Los jóvenes consiguieron una mirada general de cómo se sitúa la publicidad sobre promoción lectora en los niveles local, nacional e internacional; escenario que indica que los usos de la argumentación publicitaria trascienden las fronteras y tiene unas características generalizadas en el marco de lo que se pretende "vender" y lo que se quiere recibir. Así, la publicidad de promoción lectora se generaliza como objetivo clave en el contexto sociocultural. Este interés compartido que se visualiza en el banco de publicidad compilado muestra que nos encontramos inmersos en una sociedad de la información y, por supuesto, mediática.

Ahora bien, es indiscutible que la publicidad sobre promoción lectora se centra en fomentar un interés en un grupo de personas determinado para que la actividad lectora se convierta en un hábito fortalecido en comunidad, ante todo en familia. Podemos decir, entonces, que la publicidad sobre la promoción lectora busca tocar a las personas en su emoción, con el objetivo último de cambiar sus actitudes. Por otra parte, las publicidades recopiladas muestran una fuerte tendencia hacia el uso de las nuevas tecnologías de la información.

Se puede concluir que es interesante la interacción entre lo icónico y lo lingüístico en los afiches publicitarios compilados. En esta relación, la imagen cobra un protagonismo imprescindible para suscitar el interés de un público; en este género discursivo la imagen orienta hacia la comprensión de lo que se pretende argumentar. De su parte, la palabra se une al efecto de la imagen de una manera breve, contundente y precisa para conseguir un fin retórico: persuadir, mover, conseguir adhesión en el auditorio.

Los estudiantes reconocieron que es posible argumentar mediante la identificación, conocimiento y uso de figuras retóricas; también advirtieron que estos recursos resultan valiosos e ilustrativos para producir un afiche publicitario. A pesar de que al iniciar el proceso de intervención no reconocían algunas figuras retóricas, después del trabajo concienzudo en este tema, lograron producir un afiche publicitario que las utiliza al servicio de una intención comunicativa.

Por otra parte, los procedimientos retóricos más comunes que se visualizaron, no solo en el banco de publicidad anteriormente nombrado, sino en las producciones elaboradas por los estudiantes, son la rima, la hipérbole, la metáfora, las anáforas y la paronomasia. Es importante aclarar que no resultaba de interés que los estudiantes memorizaran las figuras retóricas, sino que aprendieran cuál era su estructura y, ante todo, qué efecto podían lograr con su uso. Justamente en una investigación del grupo de investigación DiLeMa ${ }^{1}$, documentada en el artículo La producción escrita de los estudiantes de grados 5 y 9 de Educación Básica en el marco de la preparación para las Pruebas Saber en Armenia y el Quindío, Caro, Castrillón y Rivera (2012) insistían en la necesidad trabajar en el aula el alcance perlocutivo de las figuras retóricas, apoyados en las siguientes palabras de Perelman: "Una figura es argumentativa si su empleo, que conduce a un cambio de perspectiva, parece normal con relación a la nueva situación así sugerida. Al contrario, si el discurso no logra la adhesión del auditor, la figura será percibida como ornamento, como figura de estilo que permanece ineficaz en tanto medio de persuasión" (Perelman, 1997: 64). Así las cosas, el presente proyecto pudo recoger resultados

1. El proyecto Análisis de la producción escrita de estudiantes de grados 5 y 9 de Educación Básica en el marco de la preparación para las pruebas Saber en la ciudad de Armenia y el Departamento del Quindío (2011-2012)
tuvo como base una pregunta incluida en un simulacro de Prueba Saber dirigido a grupos de grado $5^{\circ}$ y $9^{\circ}$ de las instituciones públicas. El objetivo central de la investigación partío del análisis de los textos producidos por tuvo como base una pregunta incluida en un simulacro de Prueba Saber dirigido a grupos de grado $5^{\circ}$ y $9^{\circ}$ de las instituciones públicas. El objetivo central de la investigación partí́ del análisis de los textos producidos por
los estudiantes en dicha prueba, con el fin de identificar fortalezas y debilidades en la producción textual, que permitieran generar propuestas y sugerencias en aras de mejorar las competencias en este campo. La prueba de

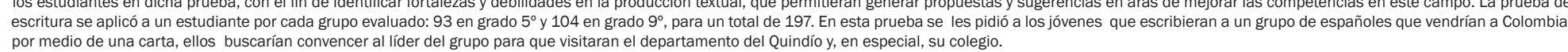


positivos en dicha recomendación, pues los estudiantes sujeto de investigación comprendieron que en el corpus de afiches publicitarios estudiados, más que figuras de ornato, había figuras retóricas precisas que conseguían el fin último de la adhesión del auditorio.

No se puede olvidar que la intervención se situaba en torno al proceso de producción de los afiches publicitarios; en dicho intento se decidió elaborar una adaptación del Modelo Didactext (2015), específicamente en cuanto a las estrategias cognitivas y metacognitivas que esta propuesta presenta. Si se mira con detenimiento, la adaptación de este modelo permitió repercutir de manera positiva no solo en la producción de los afiches publicitarios, sino en las actitudes de los estudiantes frente a la escritura en general.

Por otra parte, los estudiantes realizaban ejercicios de producción de escritura de manera improvisada y no utilizaban recursos de organización de la información para la construcción de su producto. Con la implementación de las guías de aprendizaje mediadas por el Modelo Didactext (2015), se buscó priorizar en los saberes previos, en la planificación de las actividades, en la elaboración y posterior reelaboración de un producto, lo cual les permitió pasar por diversas etapas de corrección hasta llegar a una versión final cercana a los criterios que nos habíamos trazado.

La implementación del Modelo Didactext y su adaptación al trabajo que realizamos sobre producción de textos argumentativos publicitarios sobre promoción lectora permitió afinar una reflexión, en torno al género discursivo mediador en este proceso investigativo; dicho modelo se presentó como una herramienta aplicable, también, a la elaboración de un proceso de escritura publicitaria. Todo esto demuestra la importancia didáctica del modelo en la producción de diversos tipos de textos.

Por ende, el Modelo Didactext como una herramienta útil, dinámica y versátil que es adaptable a diversas tipologías textuales como la argumentativa; valga aclarar que, este modelo se elaboró inicialmente para la producción de textos de carácter expositivo-explicativos; sin embargo, desde este proyecto de investigación se infiere que este se convierte en un recurso para el acompañamiento de distintos procesos de escritura

Desde dichas observaciones, se puede concluir que la investigación es pertinente, no solo en la consecución de resultados en el género discursivo elegido con este grupo de normalistas superiores, sino en las posibilidades de transferir cambios en la manera de mediar los procesos de escritura de sus estudiantes a los diferentes ámbitos en los que ejercerán su futuro quehacer docente.

\section{Referencias bibliográficas}

Álvarez, T. (1998). “Las ciencias del lenguaje y su transposición en el marco de la Didáctica de la lengua”. Didáctica, (10), 179-188.

Álvarez, T. (2005). Didáctica del texto en la formación del profesorado. Madrid: Síntesis.

Bajtín, M. (1982) Estética de la creación verbal, trad. T. Bubnova. Méjico: Siglo XXI.

Camps, A. (2011). “El objeto de la didáctica de la lengua y la literatura”. En Abascal, M; Larringan, L; Margallo, A; Mateos, M; Milian, M; Ribas, T y otros (eds.), Didáctica de la lengua castellana y la literatura (pp. 13-32). Barcelona: Graó.

Camps, A. (2005). Hablar en clase: cómo trabajar la lengua oral en el centro escolar. Barcelona: Grao.

Camps, A. (1993). "Didáctica de la lengua: la emergencia de un campo científico específico". Infancia y Aprendizaje 16 (62-63): 209-217

Caro, M. A., Castrillón, C. A. y Rivera, J. R. (2012). "La producción escrita de los estudiantes de grados 5 y 9 de Educación Básica en el marco de la preparación para las Pruebas Saber en Armenia y el Quindío". Sophia, (8): 60-79.

Chevallard, Y. (1998). La transposición didáctica. Del saber sabio al saber enseñado. Barcelona: Aique.

Didactext, grupo (2015). “Modelo sociocognitivo, pragmalingüístico y didáctico para la producción de textos escritos" Didáctica. Lengua y literatura 15, 77-104.

Dietcher, E. (1963). La estrategia del deseo. Buenos Aires: Huelmul. 
Dolz, J., Gagnon, R. y Mosquera S. (2009). "La didáctica de las lenguas: Una disciplina en proceso de construcción”. Didáctica. Lengua y literatura, (21): 117-141.

Dolz, J. (1995). “Escribir textos argumentativos para mejorar su comprensión”. Comunicación, Lenguaje y Educación, (25): 65-77.

Elliot, J. (2005). La investigación-acción en educación. Madrid: Morata.

Lomas, C. (1996). El espectáculo del deseo: uso y formas de la persuasión publicitaria. Barcelona: Octaedro.

Lomas, C. (1999). Cómo enseñar a hacer cosas con las palabras. Barcelona: Paidós.

Martínez, M. (2010). Ciencia y arte en la metodología cualitativa. México: Trillas.

Ministerio de Educación Nacional (2013). Leer para comprender, escribir para transformar. Bogotá: Serie Río de Letras.

Ministerio de Educación Nacional (2006). Estándares Básicos de Competencias en lenguaje, matemáticas, ciencias y ciudadanas. Bogotá.

Ministerio de Educación Nacional (1998). Lineamientos curriculares para el área de Lenguaje. Bogotá: Ministerio de Educación Nacional. Recuperado en http://www.mineducacion.gov.co/1621/articles-339975_recurso_6.pdf

Perelman, C. (1997). El imperio retórico. Bogotá: Norma.

Perelman, C. (1989). Tratado de la argumentación: Madrid: Gredos.

Péninou, G. (1972). Semiótica de la publicidad. Barcelona: Gustavo Gili.

Sánchez, C. (2014). Prácticas de lectura en el aula: orientaciones didácticas para docentes. Bogotá: Ministerio de Educación Nacional.

Sánchez, V., Dolz, J. y Borzone A. (2012). “Escribir textos argumentativos desde el inicio de la escolaridad. Un análisis de textos producidos a partir de una secuencia didáctica”. Revista Trab. Aplic., Campinas. 51(2): 409-432.

Sánchez, V. y Silva, M. (2011). "Aprendiendo a argumentar. Análisis del uso de marcas enunciativas en cartas infantiles”. Revista de Lingüística y teoría aplicada (49): 129-151 